\title{
The role of rehabilitation in the management of diabetic foot wounds
}

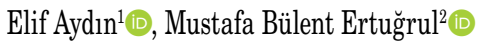 \\ ${ }^{1}$ Department of Physical Medicine and Rehabilitation, Adnan Menderes University, Faculty of Medicine, Aydnn, Turkey \\ ${ }^{2}$ Department of Infectious Diseases and Clinical Microbiology, Reyap Hospital, Istanbul, Turkey
}

Received: March 19, 2021 Accepted: August 17, 2021 Published online: December 01, 2021

\begin{abstract}
Diabetes is one of the most common health problems worldwide. Diabetic foot wounds (DFWs) are hazardous complications of the disease. Patients are often referred to rehabilitation facilities at later stages of the diabetic complications, particularly after amputation surgery. There are potential benefits of rehabilitation practices in preventing and managing DFWs. Therefore, rehabilitation needs to be more involved in the management of DFWs and should be in all stages of diabetic care. In this review, we discuss literature data to bring rehabilitation perspective to the multidisciplinary management of DFWs.
\end{abstract}

Keywords: Diabetic foot, exercise, foot ulceration, plantar pressure, rehabilitation.

Diabetes mellitus (DM) is one of the leading causes of morbidity and mortality worldwide. Its prevalence is $16.5 \%$ in Turkey, and this number has been increasing constantly. ${ }^{[1]}$ Diabetic foot wounds (DFWs) develop in 12 to $25 \%$ of all DM patients. Foot wounds are a serious health problem that negatively affects the quality of life and may result in major amputations. In addition to the difficulties experienced by the patient, the estimated financial burden of DFWs on our country is also quite high. According to a study conducted in tertiary healthcare institutions, the economic cost of a patient with DFWs is US\$ 976 per person, while of a diabetic patient without a wound is only half of that in our country. ${ }^{[2]}$ Meanwhile, several studies have shown that the probability of recurrence is $70 \%$ within five years. Considering both the morbidity and the financial impact, prevention of the development of DFWs becomes the most important goal of the healthcare providers to diabetic patients.
Peripheral neuropathy and vasculopathy are the main causes of DFWs. When sensory loss is severe, the protective senses of the plantar surface diminish, and feet become vulnerable to trauma and minor injuries. Vasculopathy, as another contributing factor causes tissue ischemia and prepares the area for wounds. However, in recent years, factors other than neuropathy and vasculopathy are thought to contribute to wound development, such as gait abnormalities, balance disorders, muscle dysfunction, and joint restrictions. These factors, per se or combined, lead to abnormal plantar pressure distribution pattern and put the foot under risk of ulceration. ${ }^{[3]}$ Data from several studies have suggested that rehabilitation can prevent or treat DFWs by modifying these etiological factors.

Management of DFWs is a multidisciplinary teamwork, and infectious diseases specialists, endocrinologists, plastic and reconstructive surgeons, orthopedic surgeons, physical medicine and rehabilitation specialists, cardiovascular surgeons,

Corresponding author: Elif Aydın, MD. Adnan Menderes Üniversitesi Tıp Fakültesi, Fiziksel Tıp ve Rehabilitasyon Anabilim Dalı, 09010 Aydın, Türkiye.

e-mail: drebulak@yahoo.com

Aydın E, Ertuğrul MB. The role of rehabilitation in the management of diabetic foot wounds. Turk J Phys Med Rehab 2021;67(4):389-398. 
diabetes nurses, diabetic wound care nurses, physiotherapists, podologists, dieticians, and social workers are the members of this team. In this review, we discuss the contribution of rehabilitation to the prevention and management of DFWs.

The role of rehabilitation in the management of DFWs can be evaluated in two periods: pre-wound and post-wound rehabilitation.

\section{Prevention of diabetic foot wounds within the context of rehabilitation}

\section{Neuropathy \& Vasculopathy}

Currently, exercise is recommended for all diabetic patients owing to its positive effects on blood glucose regulation. On the other hand, the benefits of exercise in controlling peripheral neuropathy and vasculopathy require more attention.

Although there are multiple forms of diabetic neuropathy, the most common form is distal symmetrical sensorimotor polyneuropathy with an insidious onset. ${ }^{[4]}$ Due to impaired tactile sensation, individuals with advanced polyneuropathy cannot detect trauma to their foot. In addition, balance and motor control would be affected by the loss of proprioceptive sensation. When motor neurons are also recruited, the loss of muscle strength would also be detected. These impairments altogether change the normal mechanical loading on the foot and lead to increased ulceration risk. Since this involvement mostly starts from distal and, then, progresses to proximal, the foot is the first body part to be exposed to the risk of injury with a minor trauma. ${ }^{[5,6]}$

The preventive effects of exercise on the development of polyneuropathy are primarily thanks to the control of blood glucose level and insulin resistance. Exercise also supports microvascular function and fat oxidation, reduces oxidative stress, and increases neurotrophic factors (Table 1). ${ }^{[7]}$ Studies have shown that aerobic and resistive

\section{TABLE 1}

Effects of exercise preventing the development of diabetic neuropathy

Controls body weight

Controls blood glucose level

Increases insulin sensitivity

Improves microvascular function

Increases fat oxidation

Increases neurotrophic factors exercises reduce the risk of neuropathy development in diabetic patients. ${ }^{[8-10]}$ A study which examined nerve fiber density with skin biopsies demonstrated that diet and exercise for one-year significantly increased the nerve fiber density. ${ }^{[11]}$ In a systematic review including 418 patients, physical activity and exercise increased the nerve conduction velocities and peripheral sensory function. ${ }^{[12]} \mathrm{A}$ recent systematic review showed that aerobic exercises might positively affect nerve function in patients with diabetes, but optimal dosage still remains unclear. ${ }^{[13]}$

In addition, previous studies have demonstrated the positive effects of exercise on ongoing polyneuropathy. Both aerobic and aerobic plus resistive training have shown to improve nerve conduction velocities and neuropathic symptoms. ${ }^{[7,14,15]}$ A recent randomizedcontrolled trial (RCT) investigated the effects of sensorial and gait training on proprioception, nerve function, and muscular activation in patients with diabetic peripheral neuropathy (DPN). ${ }^{[16]}$ In this study, a rehabilitation program including wall slides, bridging exercises, prone plank, sit to stand, wobble board exercises, one leg stance, heel and toe raise, tandem stance gradually progressed to different grades using unstable surface and gait training with different patterns of walking were conducted thrice a week for a total of 24 sessions. The results of this study demonstrated a significant improvement in proprioception and nerve function.

A much-debated question is whether exercise is safe for individuals who already have neuropathy. There is a common concern regarding exercise-induced foot wounds in patients with DPN due to the impaired protective sensation. For many years, diabetic patients who had neuropathy were advised to avoid weight-bearing exercises. In contrast, recent researches have demonstrated that physical activity reduces risk for skin breakdown. ${ }^{[17-20]}$ Also, aerobic exercises have shown to improve neuropathic symptoms and stimulate repair and branching of cutaneous sensory fibers. ${ }^{[7,21]}$ However, weight-bearing exercises should not be prescribed to patients who have advanced foot deformity or open foot wounds. Also, patients with absent protective sensation must avoid repetitive weight-bearing activities, such as treadmill walking. ${ }^{[7]}$

Vasculopathy is one of the most important complications of diabetes. As well as neuropathy, endothelial dysfunction and inflammation are also associated with DFWs, leading to ischemia in the tissue. Another contribution of vasculopathy for the development of DFWs is that diabetic patients with 
peripheral vascular disease have claudication and, therefore, their walking speed declines. Due to the reduced walking speed, the time spent in the stance phase of the foot is prolonged. Thus, the plantar surface is exposed to pressure for a longer time period, leading to an increased risk of DFWs. Using the most appropriate exercise programs, claudication and fatigue of these individuals can be reduced and their functional capacity can be increased. It is also known that exercise has positive effects on endothelial function, oxidative stress, and the formation of inflammatory responses. ${ }^{[22,23]}$ Moreover, physical activity can reduce the risk of DFWs by increasing tissue perfusion. A study showed that an intermittent walking program (more than $30 \mathrm{~min}$, thrice a week) significantly improved the walking speed and distance in patients with claudication. ${ }^{[24]}$ Other studies revealed that walking for $1 \mathrm{~h}$, four times a week as a homebased exercise program led to an increase in the walking speed and quality of life in diabetic patients with vasculopathy. ${ }^{[25,26]}$ Taken together, these studies indicate that walking and intermittent walking improve the walking speed and, thus, reduce the risk of vasculopathy-related DFWs.

To prevent complications of diabetic neuropathy and vasculopathy, walking and supervised exercise should be an integral part of the rehabilitation of diabetic patients. The recommendation of the American Diabetes Association (ADA) for type 2 DM patients is to perform at least $150 \mathrm{~min}$ of moderate-intensity aerobic exercise and/or $90 \mathrm{~min}$ of vigorous aerobic exercise per week. ${ }^{[27]}$ According to the 2019 update of the Clinical Practice Guideline for Diagnosis, Treatment, and Follow-up of. Diabetes Mellitus and Its Complications issued by the Diabetes Working Group of the Turkish Endocrinology and Metabolism Association, diabetic patients are advised to perform aerobic exercises (e.g., walking, running, swimming) and exercises to increase muscle strength two to three times a week. ${ }^{[28]}$ In addition, it is emphasized that flexibility and balance exercises are helpful to increase mobility, particularly in elderly patients. This guide also provides a detailed information on blood glucose control for diabetic patients who desire to exercise, and diabetes complications that may be associated with exercise. Contraindications to exercise in patients with diabetes are also described (Table 2).

\section{Joint stiffness}

Diabetic patients have an increased connective tissue thickening and stiffness in all of their main tendons and ligaments. This is clinically relevant, particularly in the foot-ankle complex, as it leads to abnormalities in plantar pressure distribution. ${ }^{[29-31]}$ There are a number of reasons for tissue stiffness such as glycosylation of collagen of the Achilles tendon and plantar fascia, ongoing inflammation, microvascular damage, and trauma. ${ }^{[32,33]}$

The stiffness of Achilles tendon and plantar fascia reduces the mobility of the foot and ankle, affecting all the rockers of the foot during walking, and decreases the shock absorption of the foot during the stance phase of the gait. Furthermore, the stiff Achilles tendon leads to an increase in the tensile force it exerts on the calcaneus. Foot dorsiflexion is restricted and plantar fascia becomes more tense, causing a cavus-type plantar loading, resulting in an increased load on the metatarsal heads. ${ }^{[34-36]}$ Together with the impaired plantar sensation, foot wounds become inevitable under these overloaded areas.

Recent studies have shown that Achilles tendon lengthening surgery reduces peak plantar pressures and accelerates healing of the wounds in the treatment of chronic diabetic foot ulcers. ${ }^{[37,38]}$ Based on these data, we can assume that the easiest way to treat foot and ankle joint limitation is not to allow its development. It has been observed that stretching exercises applied to the ankle and plantar fascia reduce plantar fascia tension and arch deformation. ${ }^{[39]}$ Also, ranges of motion exercises appear to significantly reduce the peak plantar pressures. ${ }^{[40,41]}$ However, the effectiveness of stretching exercises in preventing wound formation is still unclear in the long-term. Therefore, diabetic patients should be instructed to perform stretching and range of motion exercises for Achilles tendon, plantar fascia, triceps sura, and hamstring muscles (Figures 1 and 2).

TABLE 2

Contraindications of exercise in diabetic patients ${ }^{[2]}$

Unstable plasma glucose levels

Uncontrolled hypertension

Severe neuropathy leading to sensory loss

Active cardiovascular disease

Proliferative retinopathy (intensive exercises are contraindicated)

Vitreous bleeding

Severe hypoglycemia within the last $24 \mathrm{~h}$

Hypoglycemia unawareness

Blood glucose level $>250 \mathrm{mg} / \mathrm{dL}$ and ketone $(+)$ 

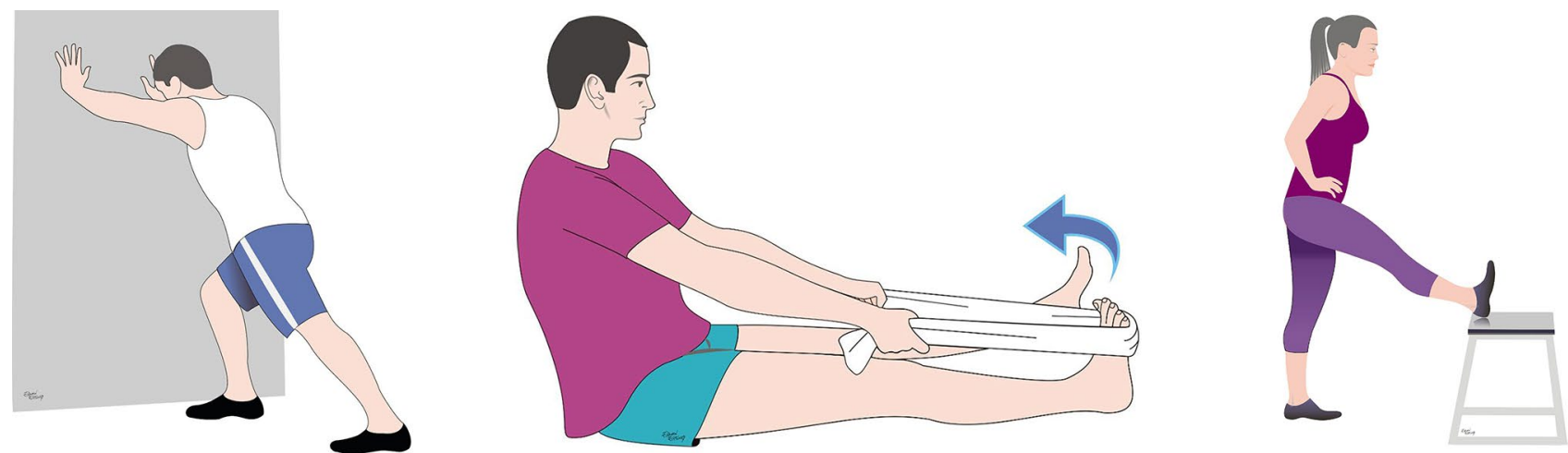

Figure 1. Lower extremity stretching exercises that can be advised to diabetic patients (with the permisson of Erman Ertung).

\section{Balance}

Balance requires visual, somatosensorial, and vestibular systems to work together. Although all these afferent and efferent systems may be affected to some extent in diabetic patients, the main problem in patients with polyneuropathy arises when the somatosensorial system is involved. Individuals with diabetes have a higher postural sway, regardless of age. ${ }^{[42,43]}$ A study have revealed a positive correlation between the hind foot peak plantar pressure and body oscillations. ${ }^{[44]}$ Impaired postural control along with the muscle weakness, joint limitations and foot deformities may lead to changes of plantar pressure distribution which may contribute to the increased risk for plantar wounds. ${ }^{[45]}$
Several studies have suggested that exercise programs for diabetic patients can improve balance and reduce risk of falls within 6 to 12 weeks. ${ }^{[46,47]}$ Balance exercises can positively affect the plantar pressure distribution and may reduce the risk of wound development. To date, however, there has been no research in the literature examining the direct association between balance training and DFWs.

\section{Gait disturbances}

Gait abnormalities are observed in diabetic patients as a result of neuropathy, joint limitations, muscle dysfunction, and foot deformities. Due to DPN, patients cannot receive tactile information from the ground and, also, there is a lack of
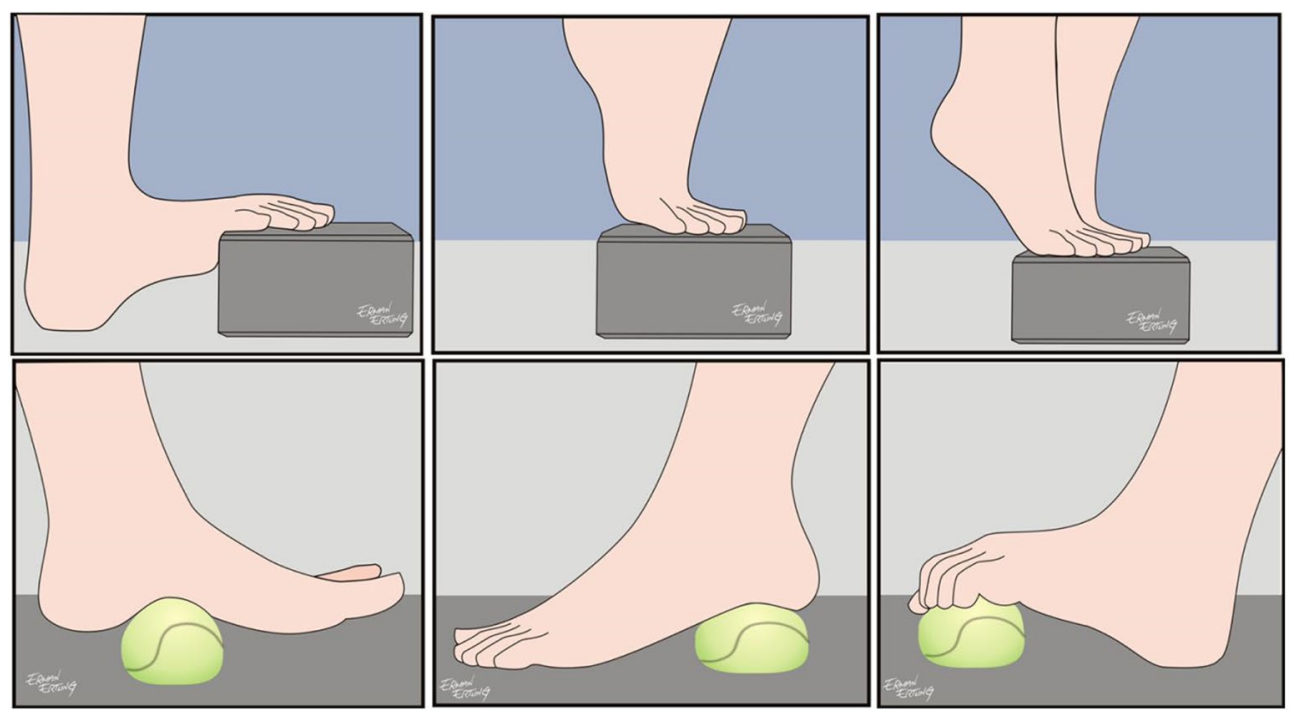

Figure 2. Plantar fascia stretching and myofascial release techniques (with the permission of Erman Ertung). 
proprioceptive inputs from foot and ankle joints. As a result, individuals develop a more cautious and slow walking pattern against falling. ${ }^{[45,48]}$ In addition, a different activity pattern of the muscles has been observed during walking in individuals with diabetes, independent of polyneuropathy. ${ }^{[49]}$ A co-contraction observed in the agonist and antagonist muscles of the ankle and knee. As a consequence, the walking speed decreases and the stance phase of the gait is prolonged, ${ }^{[48-50]}$ which may increase the risk of plantar wound development by prolonging the exposure time to pressure.

During gait, load transfer patterns under the foot also differ in patients with diabetic neuropathy. Due to the rigidity of the joints, mild pronation of the foot during normal gait does not occur, and the helical movement in the stance phase cannot be observed. ${ }^{[34,36,48]}$ Therefore, the pressure center shifts much more medial than the physiological transition point, causing abnormal loadings on the sole of the foot which may increase risk for DFWs. ${ }^{[51]}$

To adjust gait abnormalities, muscle atrophy and joint mobility should be restored with exercises that include range of motion, balance, aerobic and resistive training. Increased postural stability and muscle quality would positively affect walking performance, thereby, reducing the risk of wound development by preventing incorrect loading on the plantar surface.

To date, several studies have focused on different gait modifications to reduce forefoot plantar pressure in diabetic patients with neuropathy. Two different studies demonstrated mild reduction in forefoot peak plantar pressures, when participants with neuropathy were instructed to pull their leg forward from the hip to initiate the swing phase of the gait rather than push off. However, the authors suggested that the patients were unable to use this pattern long term. ${ }^{[52,53]}$ Brown et al. ${ }^{[43]}$ reported a reduction in peak plantar pressures under forefoot with using the "step to" gait in patients with DPN. Studies evaluating the impact of biofeedback-based walking strategy in patients with DPN have shown that the insoles with biofeedback provide safe and balanced plantar pressure distribution, if there is no foot deformity. ${ }^{[54,55]}$ In recent years, retro walking has been a popular treatment in rehabilitation. The walking cycle, which we start with heel strike in our normal gait, starts with finger contact when we walk back and forth, and this affects the entire plantar pressure distribution. In a study, a decline in forefoot plantar pressure was observed after a total of 12 weeks of back-walking exercise. ${ }^{[56]}$ Taken together, these studies suggest that gait modifications may be able to balance plantar pressures in patients with diabetes. On the other hand, the method chosen should be sustainable and should not disrupt the patient's natural posture and create additional harmful biomechanical loads.

\section{Management of DFWs within the context of rehabilitation}

Although our main goal is to prevent DFW formation, they inevitably occur in 12 to $25 \%$ of diabetic patients. A positive contribution can be made to wound healing with rehabilitation practices.

The impact of exercise in diabetic wound healing

The main goals of exercise prescription in patients with DFWs are to prevent new wounds on the contralateral side, to help glycemic control, to prevent the side effects of immobility, and to accelerate the healing of the wound.

Individuals with foot wounds often become bedridden or a wheelchair user, until the wound heals. Immediate mobilization of these patients is necessary to avoid complications of immobilization, particularly loss of muscle strength and pressure sores. As well as providing glycemic control, exercise would also have positive effects on diabetic wound healing by increasing vascularization around the adjacent area. Providing better blood circulation of the wound bed facilitates the formation of new granulation tissue and increases nutrition and oxygenation.

In case of a present wound, loading on the affected extremity can be harmful due to its negative effect on wound healing and presence of wound dressing materials, negative pressure devices or tissue flaps on the affected area. Therefore, exercises must be either partial weight bearing or non-weight bearing. Depending on the condition of the wound, non-weight bearing or partial weight bearing aerobic exercises such as swimming, static cycling should be prescribed as a part of the treatment plan. ${ }^{[57]}$ While prescribing exercise programs to individuals with unilateral wounds, care should be taken not to overload the healthy side to prevent new wounds. In future practice, it seems possible to use treadmills with lift assistance to provide motion without harmless loads on wounded feet. In a study conducted in our country, there was a significant decrease in wound sizes of patients who were instructed to do ankle-foot range of motion exercises for 12 weeks. ${ }^{[58]}$ In the light of these data, we suggest that ankle and foot range of motion exercises should be recommended for all individuals with DFWs 
(Figure 3). In addition, aerobic exercises should be added to the treatment plan for patients without contraindications.

Offloading braces are frequently used in individuals with DFWs, and there are concerns that they can be injurious by causing excessive loads on the healthy side. In addition, offloading braces can impair balance and, when the decreased sensorineural impulse and muscle dysfunctions of these patients are taken into account, the risk of falling increases inevitably. ${ }^{[59]}$ It is also the responsibility of our branch to select the correct assistive walking device suitable for the patients' age and physical performance and to teach how to use them. Also, balance exercises should be given to these patient groups. Additionally, correction of the leg length discrepancies with a shoe lift to the healthy side is important in providing body balance and preventing back pain. These types of shoe lifts can be provided as custom made or over the counter products (Figure 4).

The role of physical therapy modalities in wound healing

Physical therapy modalities have been used in wound healing for many years. The most commonly used modalities are electrical stimulation (ES), ultrasound (US), and phototherapy. There are many reviews in the literature comparing these methods with each other and/or with placebo. Physical modalities are shown to have a positive impact on wound healing. ${ }^{[60-62]}$ However, there is no definite consensus regarding their superiority to each other. Although we have briefly summarized the use of physical therapy modalities for wound healing in terms of subject integrity, this issue should be discussed with a detailed review, which is out of the scope of this article.

\section{Electrical stimulation}

Electrical stimulation helps us to direct the desired cells in the tissues to the target area with the help of its polarity. With ES, macrophages, epidermal cells, and inactive neutrophils are migrated to the cathode, while neutrophils, fibroblasts, mast cells, platelets, lymphocytes and keratinocytes are located at the anode. In the inflammation phase of the wound healing (within the first 20 days), the negative pole is recommended to be placed close to the wound. Therefore, cells against inflammation can be attracted near to the wound site. Close placement of the positive pole to the wound site is preferred, if necrosis is dominant and there is no inflammation at the
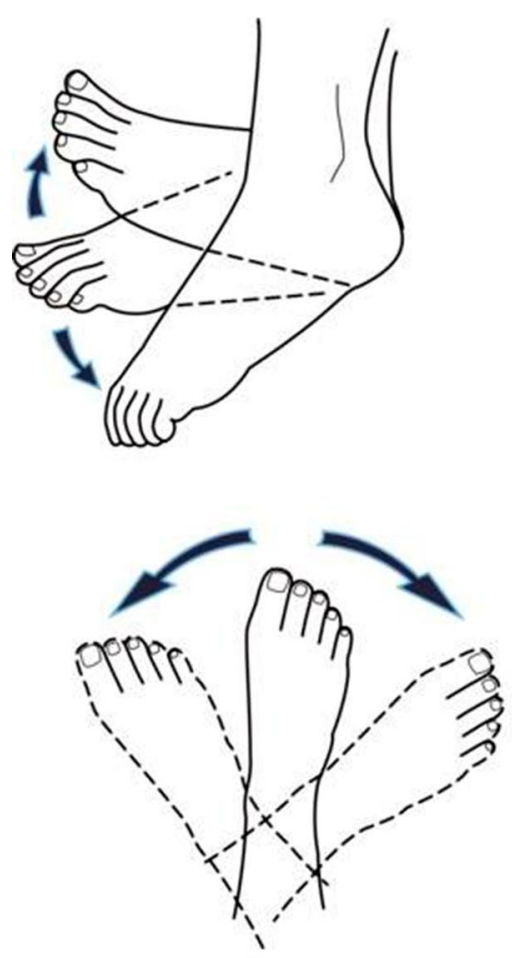
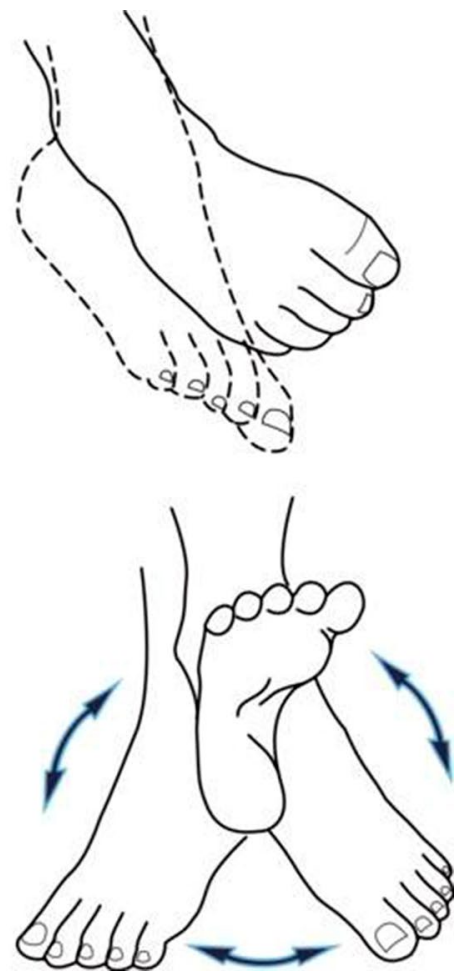

Figure 3. Foot and ankle range of motion exercises should be given even the patient had a wound or not (with the permission of Erman Ertung). 


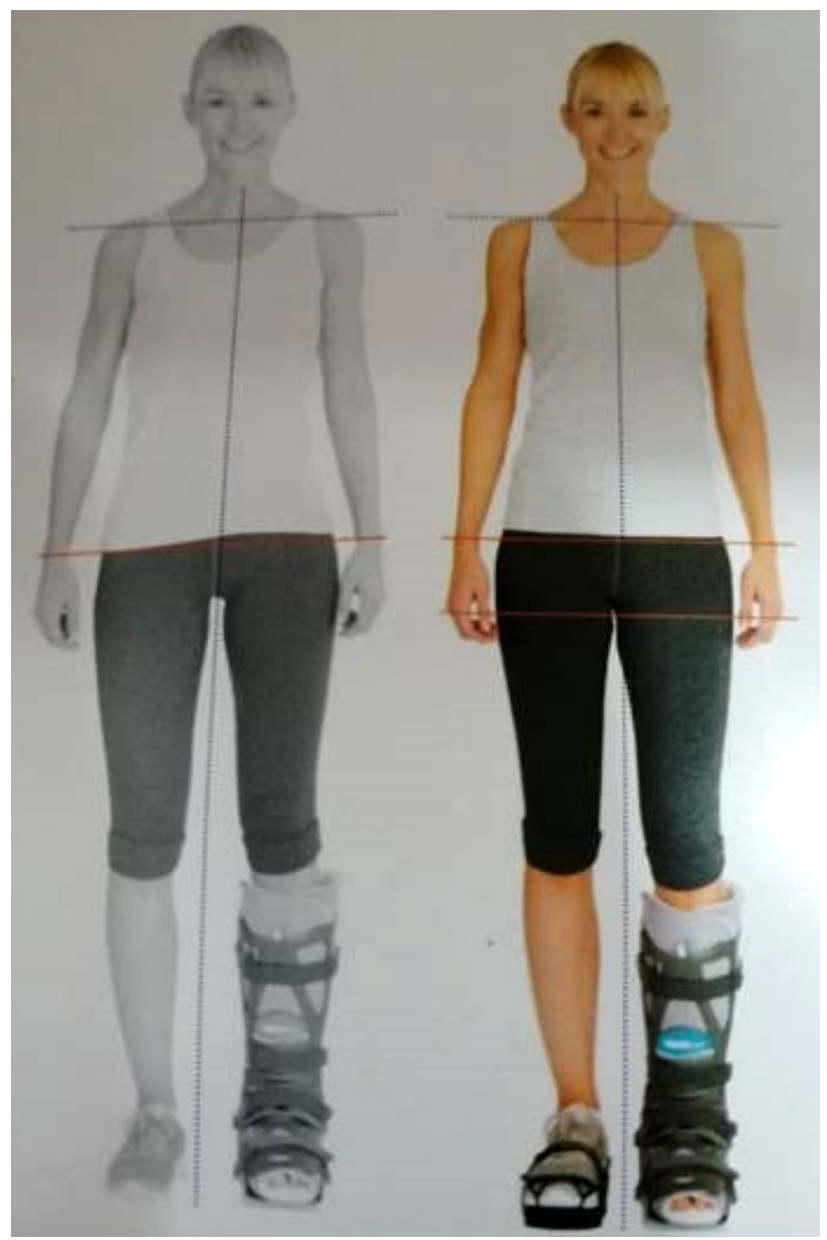

Figure 4. Correction of the leg length discrepancy with a shoe lift to the healthy side in a patient using off-loading brace (with the permission of Ottobock $^{\circledast}$ ).

wound or if the wound healing is in the proliferative phase. ${ }^{[63]}$ The mechanism of electrical currents on wound healing is summarized in Table 3 . There is still uncertainty regarding clinical impact of ES on wound healing. ${ }^{[64-66]}$ Also, appropriate current types and dosages still remain unclear. A meta-analysis revealed the use of symmetrical biphasic, monophasic or square-wave pulse waveforms in high-quality RCTs and found all of them to be effective regarding wound healing rates. ${ }^{[67]}$ In our clinic, we prefer using highvoltage pulsed currents with current parameters of 60 to 120 pps frequency, 40 to $100 \mu$ sec pulse width, and 45 to 60 -min treatment duration.

\section{Ultrasound}

Non-thermal effects of US are predominantly responsible from tissue healing. The increasing rate of protein production by fibroblasts, vasodilatation, promotion of macrophage responsiveness are the main mechanisms of tissue repair obtained from US. There are a number of qualified studies showing that US accelerates the healing in diabetic wounds. A qualified RCT revealed that US, applied on DFWs at a frequency of $40 \mathrm{kHz}$, provided a faster healing. ${ }^{[68]}$ An in vivo study indicated that noncontact, low-frequency US therapy thrice a week exhibited a better neovascularization and wound closure in a humanized excisional wound model. ${ }^{[69]}$ A controlled study found that US delivered through a mist of saline to the wounds accelerated the repair process in diabetic mice. ${ }^{[70]}$ A recent study also revealed a significantly faster reduction in the wound size with a low-frequency $(20 \mathrm{kHz})$ and low-intensity US. ${ }^{[7]}$ Although there is still uncertainty regarding effectiveness and dosage, low-intensity and low-frequency US therapy seems to be effective on wound healing.

\section{Phototherapy}

Phototherapy is another treatment modality which has a stimulating effect on cells and accelerates wound healing (Table 4). Low-level laser therapy (LLLT) is known to increase collagen production, vasodilatation and nerve conduction velocity, and reduce bacterial growth, as well. ${ }^{[63,72,73]}$ Animal studies have demonstrated potential beneficial effects of LLLT on wound healing. ${ }^{[72-74]}$ A meta-analysis of seven RCTs including 194 patients reported that

\section{TABLE 3}

Effects of electrical stimulation on tissue healing

Attracting cells to the wound area

Release of cell contents to the environment by disrupting cell membrane functions

Reducing edema

Antimicrobial activity

Increasing protein synthesis

Increasing circulation and tissue oxygenation

\section{TABLE 4}

Effects of phototherapy on tissue healing

Increasing ATP production

Increasing collagen production

Controlling inflammation

Reducing bacterial growth

Increasing vasodilation

Increasing nerve conduction velocity and regeneration

ATP: Adenosine triphosphate. 
LLLT promoted a faster granulation formation with shorter wound closure time and alleviation of foot ulcer pain. ${ }^{[75]}$ Although the ideal LLLT parameters for wound healing have not been established yet, an energy density between 5 and $24 \mathrm{~J} / \mathrm{cm}^{2}$ is considered to be the most effective range. ${ }^{[76,77]}$ In the literature, it is suggested that energy under this intensity would not be sufficient for healing, whereas higher doses can inhibit healing. ${ }^{[77-79]}$

In conclusion, with appropriate aerobic, strengthening, balance and flexibility exercises, the risk of diabetic wound development can be reduced. Wound healing also benefits from exercise and physical therapy modalities. Additionally, it is important to mobilize patients who have DFWs to minimize complications of prolonged immobilization. In the light of the literature review, rehabilitation is safe and effective in preventing and managing DFWs.

\section{Acknowledgements}

We would like to express our deep gratitude to Erman Ertung and Alp Ertung for their precious drawings.

Declaration of conflicting interests

The authors declared no conflicts of interest with respect to the authorship and/or publication of this article.

\section{Funding}

The authors received no financial support for the research and/or authorship of this article.

\section{REFERENCES}

1. Satman I, Omer B, Tutuncu Y, Kalaca S, Gedik S, Dinccag $\mathrm{N}$, et al. Twelve-year trends in the prevalence and risk factors of diabetes and prediabetes in Turkish adults. Eur J Epidemiol 2013;28:169-80.

2. Keskek SO, Kirim S, Yanmaz N. Estimated costs of the treatment of diabetic foot ulcers in a tertiary hospital in Turkey. Pak J Med Sci 2014;30:968-71.

3. Francia P, Gulisano M, Anichini R, Seghieri G. Diabetic foot and exercise therapy: Step by step the role of rigid posture and biomechanics treatment. Curr Diabetes Rev 2014;10:86-99.

4. Ziegler D. Current concepts in the management of diabetic polyneuropathy. Curr Diabetes Rev 2011;7:208-20.

5. Apelqvist J. Diagnostics and treatment of the diabetic foot. Endocrine 2012;41:384-97.

6. Boulton AJ, Kirsner RS, Vileikyte L. Clinical practice. Neuropathic diabetic foot ulcers. $N$ Engl J Med 2004;351:48-55.

7. Kluding PM, Pasnoor $M$, Singh $R$, Jernigan S, Farmer $\mathrm{K}$, Rucker J, et al. The effect of exercise on neuropathic symptoms, nerve function, and cutaneous innervation in people with diabetic peripheral neuropathy. J Diabetes Complications 2012;26:424-9.
8. Balducci S, Iacobellis G, Parisi L, Di Biase N, Calandriello E, Leonetti F, et al. Exercise training can modify the natural history of diabetic peripheral neuropathy. J Diabetes Complications 2006;20:216-23.

9. Smith AG, Russell J, Feldman EL, Goldstein J, Peltier A, Smith S, et al. Lifestyle intervention for pre-diabetic neuropathy. Diabetes Care 2006;29:1294-9.

10. Kluding PM, Pasnoor M, Singh R, Jernigan S, Farmer $\mathrm{K}$, Rucker J, et al. The effect of exercise on neuropathic symptoms, nerve function, and cutaneous innervation in people with diabetic peripheral neuropathy. J Diabetes Complications 2012;26:424-9.

11. Smith AG, Russell J, Feldman EL, Goldstein J, Peltier A, Smith S, et al. Lifestyle intervention for pre-diabetic neuropathy. Diabetes Care 2006;29:1294-9.

12. Matos M, Mendes R, Silva AB, Sousa N. Physical activity and exercise on diabetic foot related outcomes: A systematic review. Diabetes Res Clin Pract 2018;139:81-90.

13. Gu Y, Dennis SM, Kiernan MC, Harmer AR. Aerobic exercise training may improve nerve function in type 2 diabetes and pre-diabetes: A systematic review. Diabetes Metab Res Rev 2019;35:e3099.

14. Dixit S, Maiya AG, Shastry BA. Effect of aerobic exercise on peripheral nerve functions of population with diabetic peripheral neuropathy in type 2 diabetes: A single blind, parallel group randomized controlled trial. J Diabetes Complications 2014;28:332-9.

15. Fischer T, Peisker U, Fiedor S, Slowinski T, Wedemeyer P, Diekmann F, et al. Significant differentiation of focal breast lesions: Raw data-based calculation of strain ratio. Ultraschall Med 2012;33:372-9.

16. Ahmad I, Verma S, Noohu MM, Shareef MY, Hussain ME. Sensorimotor and gait training improves proprioception, nerve function, and muscular activation in patients with diabetic peripheral neuropathy: A randomized control trial. J Musculoskelet Neuronal Interact 2020;20:234-48.

17. Maluf KS, Mueller MJ. Novel Award 2002. Comparison of physical activity and cumulative plantar tissue stress among subjects with and without diabetes mellitus and a history of recurrent plantar ulcers. Clin Biomech (Bristol, Avon) 2003;18:567-75.

18. Lemaster JW, Reiber GE, Smith DG, Heagerty PJ, Wallace C. Daily weight-bearing activity does not increase the risk of diabetic foot ulcers. Med Sci Sports Exerc 2003;35:1093-9.

19. Armstrong DG, Lavery LA, Holtz-Neiderer K, Mohler MJ, Wendel CS, Nixon BP, et al. Variability in activity may precede diabetic foot ulceration. Diabetes Care 2004;27:1980-4.

20. Mueller MJ, Tuttle LJ, Lemaster JW, Strube MJ, McGill JB, Hastings MK, et al. Weight-bearing versus nonweightbearing exercise for persons with diabetes and peripheral neuropathy: A randomized controlled trial. Arch Phys Med Rehabil 2013;94:829-38.

21. Singleton JR, Smith AG, Marcus RL. Exercise as therapy for diabetic and prediabetic neuropathy. Curr Diab Rep 2015;15:120. 
22. Balducci S, Zanuso S, Cardelli P, Salerno G, Fallucca S, Nicolucci A, et al. Italian Diabetes Exercise Study (IDES) Investigators. Supervised exercise training counterbalances the adverse effects of insulin therapy in overweight/obese subjects with type 2 diabetes. Diabetes Care 2012;35:39-41.

23. Tucker PS, Fisher-Wellman K, Bloomer RJ. Can exercise minimize postprandial oxidative stress in patients with type 2 diabetes? Curr Diabetes Rev 2008;4:309-19.

24. McDermott MM, Ades P, Guralnik JM, Dyer A, Ferrucci L, Liu K, et al. Treadmill exercise and resistance training in patients with peripheral arterial disease with and without intermittent claudication: A randomized controlled trial. JAMA 2009;301:165-74.

25. Collins TC, Lunos S, Carlson T, Henderson K, Lightbourne M, Nelson B, et al. Effects of a home-based walking intervention on mobility and quality of life in people with diabetes and peripheral arterial disease: A randomized controlled trial. Diabetes Care 2011;34:2174-9.

26. McDermott MM, Liu K, Guralnik JM, Criqui MH, Spring $\mathrm{B}$, Tian L, et al. Home-based walking exercise intervention in peripheral artery disease: A randomized clinical trial. JAMA 2013;310:57-65.

27. Colberg SR, Sigal RJ, Fernhall B, Regensteiner JG, Blissmer BJ, Rubin RR, et al.; American College of Sports Medicine; American Diabetes Association. Exercise and type 2 diabetes: the American College of Sports Medicine and the American Diabetes Association: joint position statement. Diabetes Care 2010;33:e147-67.

28. Ulusal Diyabet Konsensus Grubu. Diyabet Tanı ve Tedavi Rehberi 2019. İstanbul: Armoni Nüans Baskı Sanatları A.Ş.; 2019.

29. Batista F, Nery C, Pinzur M, Monteiro AC, de Souza $\mathrm{EF}$, Felippe $\mathrm{FH}$, et al. Achilles tendinopathy in diabetes mellitus. Foot Ankle Int 2008;29:498-501.

30. Grant WP, Sullivan R, Sonenshine DE, Adam M, Slusser JH, Carson KA, et al. Electron microscopic investigation of the effects of diabetes mellitus on the Achilles tendon. J Foot Ankle Surg 1997;36:272-8.

31. Duffin AC, Lam A, Kidd R, Chan AK, Donaghue KC. Ultrasonography of plantar soft tissues thickness in young people with diabetes. Diabet Med 2002;19:1009-13.

32. Benitez-Aguirre PZ, Craig ME, Jenkins AJ, Gallego PH, Cusumano J, Duffin AC, et al. Plantar fascia thickness is longitudinally associated with retinopathy and renal dysfunction: A prospective study from adolescence to adulthood. J Diabetes Sci Technol 2012;6:348-55.

33. Couppé C, Svensson RB, Kongsgaard M, Kovanen V, Grosset JF, Snorgaard O, et al. Human Achilles tendon glycation and function in diabetes. J Appl Physiol (1985) 2016;120:130-7.

34. D’Ambrogi E, Giacomozzi C, Macellari V, Uccioli L. Abnormal foot function in diabetic patients: The altered onset of Windlass mechanism. Diabet Med 2005;22:1713-9.

35. D'Ambrogi E, Giurato L, D'Agostino MA, Giacomozzi C, Macellari V, Caselli A, et al. Contribution of plantar fascia to the increased forefoot pressures in diabetic patients. Diabetes Care 2003;26:1525-9.
36. Giacomozzi C, D'Ambrogi E, Uccioli L, Macellari V. Does the thickening of Achilles tendon and plantar fascia contribute to the alteration of diabetic foot loading? Clin Biomech (Bristol, Avon) 2005;20:532-9.

37. Nishimoto GS, Attinger CE, Cooper PS. Lengthening the Achilles tendon for the treatment of diabetic plantar forefoot ulceration. Surg Clin North Am 2003;83:707-26.

38. Hastings MK, Mueller MJ, Sinacore DR, Salsich GB, Engsberg JR, Johnson JE. Effects of a tendo-Achilles lengthening procedure on muscle function and gait characteristics in a patient with diabetes mellitus. J Orthop Sports Phys Ther 2000;30:85-90.

39. Flanigan RM, Nawoczenski DA, Chen L, Wu H, DiGiovanni BF. The influence of foot position on stretching of the plantar fascia. Foot Ankle Int 2007;28:815-22.

40. Goldsmith JR, Lidtke RH, Shott S. The effects of range-of-motion therapy on the plantar pressures of patients with diabetes mellitus. J Am Podiatr Med Assoc 2002;92:483-90.

41. Cerrahoglu L, Koşan U, Sirin TC, Ulusoy A. Range of motion and plantar pressure evaluation for the effects of self-care foot exercises on diabetic patients with and without neuropathy. J Am Podiatr Med Assoc 2016;106:189-200.

42. Kukidome D, Nishikawa T, Sato M, Nishi Y, Shimamura $\mathrm{R}$, Kawashima J, et al. Impaired balance is related to the progression of diabetic complications in both young and older adults. J Diabetes Complications 2017;31:1275-82.

43. Brown SJ, Handsaker JC, Bowling FL, Boulton AJ, Reeves ND. Diabetic peripheral neuropathy compromises balance during daily activities. Diabetes Care 2015;38:1116-22.

44. Anjos DM, Gomes LP, Sampaio LM, Correa JC, Oliveira CS. Assessment of plantar pressure and balance in patients with diabetes. Arch Med Sci 2010;6:43-8.

45. Cavanagh PR, Simoneau GG, Ulbrecht JS. Ulceration, unsteadiness, and uncertainty: The biomechanical consequences of diabetes mellitus. J Biomech 1993;26 Suppl 1:23-40.

46. Morrison S, Colberg SR, Mariano M, Parson HK, Vinik AI. Balance training reduces falls risk in older individuals with type 2 diabetes. Diabetes Care 2010;33:748-50.

47. Allet L, Armand S, de Bie RA, Golay A, Monnin D, Aminian $\mathrm{K}$, et al. The gait and balance of patients with diabetes can be improved: A randomised controlled trial. Diabetologia 2010;53:458-66

48. Raspovic A. Gait characteristics of people with diabetesrelated peripheral neuropathy, with and without a history of ulceration. Gait Posture 2013;38:723-8.

49. Sawacha Z, Spolaor F, Guarneri G, Contessa P, Carraro E, Venturin A, et al. Abnormal muscle activation during gait in diabetes patients with and without neuropathy. Gait Posture 2012;35:101-5.

50. Kwon OY, Minor SD, Maluf KS, Mueller MJ. Comparison of muscle activity during walking in subjects with and without diabetic neuropathy. Gait Posture 2003;18:105-13.

51. Giacomozzi C, Caselli A, Macellari V, Giurato L, Lardieri L, Uccioli L. Walking strategy in diabetic patients with peripheral neuropathy. Diabetes Care 2002;25:1451-7. 
52. Mueller MJ, Sinacore DR, Hoogstrate S, Daly L. Hip and ankle walking strategies: Effect on peak plantar pressures and implications for neuropathic ulceration. Arch Phys Med Rehabil 1994;75:1196-200.

53. York RM, Perell-Gerson KL, Barr M, Durham J, Roper JM. Motor learning of a gait pattern to reduce forefoot plantar pressures in individuals with diabetic peripheral neuropathy. PM R 2009;1:434-41.

54. Pataky Z, de León Rodriguez D, Allet L, Golay A, Assal M, Assal JP, et al. Biofeedback for foot offloading in diabetic patients with peripheral neuropathy. Diabet Med 2010;27:61-4.

55. De León Rodriguez D, Allet L, Golay A, Philippe J, Assal JP, Hauert CA, et al. Biofeedback can reduce foot pressure to a safe level and without causing new at-risk zones in patients with diabetes and peripheral neuropathy. Diabetes Metab Res Rev 2013;29:139-44.

56. Zhang X, Zhang Y, Gao X, Wu J, Jiao X, Zhao J, et al. Investigating the role of backward walking therapy in alleviating plantar pressure of patients with diabetic peripheral neuropathy. Arch Phys Med Rehabil 2014;95:832-9.

57. Kanade RV, van Deursen RW, Harding K, Price P. Walking performance in people with diabetic neuropathy: Benefits and threats. Diabetologia 2006;49:1747-54.

58. Eraydin Ş, Avşar G. The effect of foot exercises on wound healing in type 2 diabetic patients with a foot ulcer: A randomized control study. J Wound Ostomy Continence Nurs 2018;45:123-30.

59. van Deursen R. Footwear for the neuropathic patient: Offloading and stability. Diabetes Metab Res Rev 2008;24 Suppl 1:S96-S100.

60. Kloth LC. Electrical stimulation for wound healing: a review of evidence from in vitro studies, animal experiments, and clinical trials. Int J Low Extrem Wounds 2005;4:23-44.

61. Kwan RL, Cheing GL, Vong SK, Lo SK. Electrophysical therapy for managing diabetic foot ulcers: a systematic review. Int Wound J 2013;10:121-31.

62. Cameron MH. Physical agents in rehabilitation: from research to practice. 4 th ed. St. Louis: Elsevier/Saunders; 2013

63. Cameron MH. Physical agents in rehabilitation: From research to practice. 4 th ed. St. Louis: Saunders; 2013

64. Peters EJ, Lavery LA, Armstrong DG, Fleischli JG. Electric stimulation as an adjunct to heal diabetic foot ulcers: A randomized clinical trial. Arch Phys Med Rehabil 2001;82:721-5.

65. Petrofsky JS, Lawson D, Berk L, Suh H. Enhanced healing of diabetic foot ulcers using local heat and electrical stimulation for $30 \mathrm{~min}$ three times per week. J Diabetes 2010;2:41-6.

66. Baker LL, Chambers R, DeMuth SK, Villar F. Effects of electrical stimulation on wound healing in patients with diabetic ulcers. Diabetes Care 1997;20:405-12.
67. Kwan RL, Cheing GL, Vong SK, Lo SK. Electrophysical therapy for managing diabetic foot ulcers: A systematic review. Int Wound J 2013;10:121-31.

68. Ennis WJ, Foremann P, Mozen N, Massey J, ConnerKerr T, Meneses P. Ultrasound therapy for recalcitrant diabetic foot ulcers: Results of a randomized, doubleblind, controlled, multicenter study. Ostomy Wound Manage 2005;51:24-39.

69. Maan ZN, Januszyk M, Rennert RC, Duscher D, Rodrigues $M$, Fujiwara $T$, et al. Noncontact, low-frequency ultrasound therapy enhances neovascularization and wound healing in diabetic mice. Plast Reconstr Surg 2014;134:402e-411e.

70. Thawer HA, Houghton PE. Effects of ultrasound delivered through a mist of saline to wounds in mice with diabetes mellitus. J Wound Care 2004;13:171-6.

71. Bajpai A, Nadkarni S, Neidrauer M, Weingarten MS, Lewin PA, Spiller KL. Effects of non-thermal, non-cavitational ultrasound exposure on human diabetic ulcer healing and inflammatory gene expression in a pilot study. Ultrasound Med Biol 2018;44:2043-9.

72. Adamskaya N, Dungel P, Mittermayr R, Hartinger J, Feichtinger G, Wassermann K, et al. Light therapy by blue LED improves wound healing in an excision model in rats. Injury 2011;42:917-21.

73. Posten W, Wrone DA, Dover JS, Arndt KA, Silapunt S, Alam M. Low-level laser therapy for wound healing: Mechanism and efficacy. Dermatol Surg 2005;31:334-40.

74. Rezende SB, Ribeiro MS, Núñez SC, Garcia VG, Maldonado EP. Effects of a single near-infrared laser treatment on cutaneous wound healing: Biometrical and histological study in rats. J Photochem Photobiol B 2007;87:145-53.

75. Li S, Wang C, Wang B, Liu L, Tang L, Liu D, et al. Efficacy of low-level light therapy for treatment of diabetic foot ulcer: A systematic review and meta-analysis of randomized controlled trials. Diabetes Res Clin Pract 2018;143:215-24.

76. Woodruff LD, Bounkeo JM, Brannon WM, Dawes KS, Barham CD, Waddell DL, et al. The efficacy of laser therapy in wound repair: A meta-analysis of the literature. Photomed Laser Surg 2004;22:241-7.

77. Hawkins D, Abrahamse H. Effect of multiple exposures of low-level laser therapy on the cellular responses of wounded human skin fibroblasts. Photomed Laser Surg 2006;24:705-14.

78. Houreld NN, Abrahamse H. Laser light influences cellular viability and proliferation in diabetic-wounded fibroblast cells in a dose- and wavelength-dependent manner. Lasers Med Sci 2008;23:11-8.

79. Mendez TM, Pinheiro AL, Pacheco MT, Nascimento PM, Ramalho LM. Dose and wavelength of laser light have influence on the repair of cutaneous wounds. J Clin Laser Med Surg 2004;22:19-25. 